\title{
Composite beams with indented construction joint - comparison of results of laboratory tests and numerical analysis
}

\author{
Grzegorz Sadowski ${ }^{1}$, Piotr Wiliński ${ }^{2}$, Anna Halicka ${ }^{3}$ \\ ${ }^{1}$ Division of Mechanics of Structures and Building Materials; Faculty of Civil Engineering, Mechanics \\ and Petrochemistry; Warsaw University of Technology; 17 Łukasiewicza Street, 09-400 Płock, Poland; \\ Grzegorz.Sadowski@pw.edu.pl: (DD 0000-0001-6441-0875 \\ ${ }^{2}$ Division of Building Structures and Technologies; Faculty of Civil Engineering, Mechanics and \\ Petrochemistry; Warsaw University of Technology; 17 Łukasiewicza Street, 09-400 Płock, Poland; \\ Piotr.Wilinski@pw.edu.pl: (iD 0000-0002-8599-5099 \\ ${ }^{3}$ Department of Building Structures; Faculty of Civil Engineering and Architecture; \\ Lublin University of Technology; 40 Nadbystrzycka Street, 20-618 Lublin, Poland; \\ a.halicka@pollub.pl iD 0000-0001-5526-8862
}

Funding: The paper was written as a part of scientific research financed from the statutory funds of the Faculty of Civil Engineering, Mechanics and Petrochemistry of the Warsaw University of Technology.

Abstract: The paper presents a comparative analysis of the behaviour of a composite beam, consisting of a precast element with indented surface and new concrete layer, subjected to 4-point bending. The results obtained from the virtual model of the beam created using the finite element method (Abaqus/CEA 2019 software) were compared with the laboratory test results obtained with use of the digital image correlation (DIC) method for identifying the crack pattern. The virtual model of composite beam was calibrated by the choice of interface parameters ensuring that the value of load resulting in delamination between concrete layers was close to that value obtained in the laboratory tests. The comparative analysis showed that the pattern of bending and shear cracks and the pattern of interface crack obtained with the finite element method reflect the laboratory test results properly. It can be assumed that the crack between concrete layers is related to the appearance and propagation of shear cracks. On the basis of FEM analysis it can be concluded that the phenomena identified as "shear friction" and "dowel action" are significantly activated after the interface cracking.

Keywords: composite concrete beam, interface shear resistance, crack, digital image correlation (DIC), finite element method (FEM) 


\section{Introduction}

The subject of this paper is concrete composite beam consisted of two parts: down part simulating the precast member with indented joint surface and an upper layer of new concrete simulating the in-situ concrete. A comparative analysis of the composite beam behaviour under the four-point bending was carried out using digital image correlation method (DIC) and the finite element method carried out with use of Abaqus/CEA 2019.

The joining mechanisms in the indented interface between concrete layers cast at different times is not exactly known. The transfer of stress between concrete layers is a pluricasual phenomenon. Its complexity is increased by the fact that the influence of each individual joint mechanism on the stress transfer is different and depends on the load level [1]-[3]. Based on the above statement, a hypothesis was formulated that it is possible to create a virtual model of composite beam with an indented interface, calibrate it on the basis on test results obtained with the use of the DIC method, and then to read out the stress that causes the interface cracking and to portray the crack pattern. The calibration of a composite beam model was carried out by the choice of interface parameters ensuring the value of load resulting in delamination between concrete layers is close to that value obtained from the laboratory tests.

The literature presents attempts of such an approach. The authors [4], [5] created a virtual model of steel-concrete composite beam, calibrated it and found out that such a scientific approach allows reflecting phenomena in this type of connection. In the paper [6], the authors proposed verification of a FEM 3D model of a reinforced concrete beam with test results carried out using the ARAMIS system. They obtained vertical deflection and cracks pattern similar to experimental results.

The comparison of results of both test methods used for reinforced concrete composite beams with the intended interface presented in this paper allows analysing the cracks and stress in the interface, as well as to describe the mechanism of damage such a composite beam. The interface parameters obtained from the calibration of a virtual model of the assumed geometric parameters of notches can be used for the analysis of composite beams with the notches of different geometry.

\section{Materials and methods}

\subsection{Preparation of elements for testing}

The tested beam consisted of a precast element with dimensions of $3000 \times 150 \times 250 \mathrm{~mm}$, with the upper surface shaped with notches of $80 \mathrm{~mm}$ spacing and new concrete of $70 \mathrm{~mm}$ thickness. 

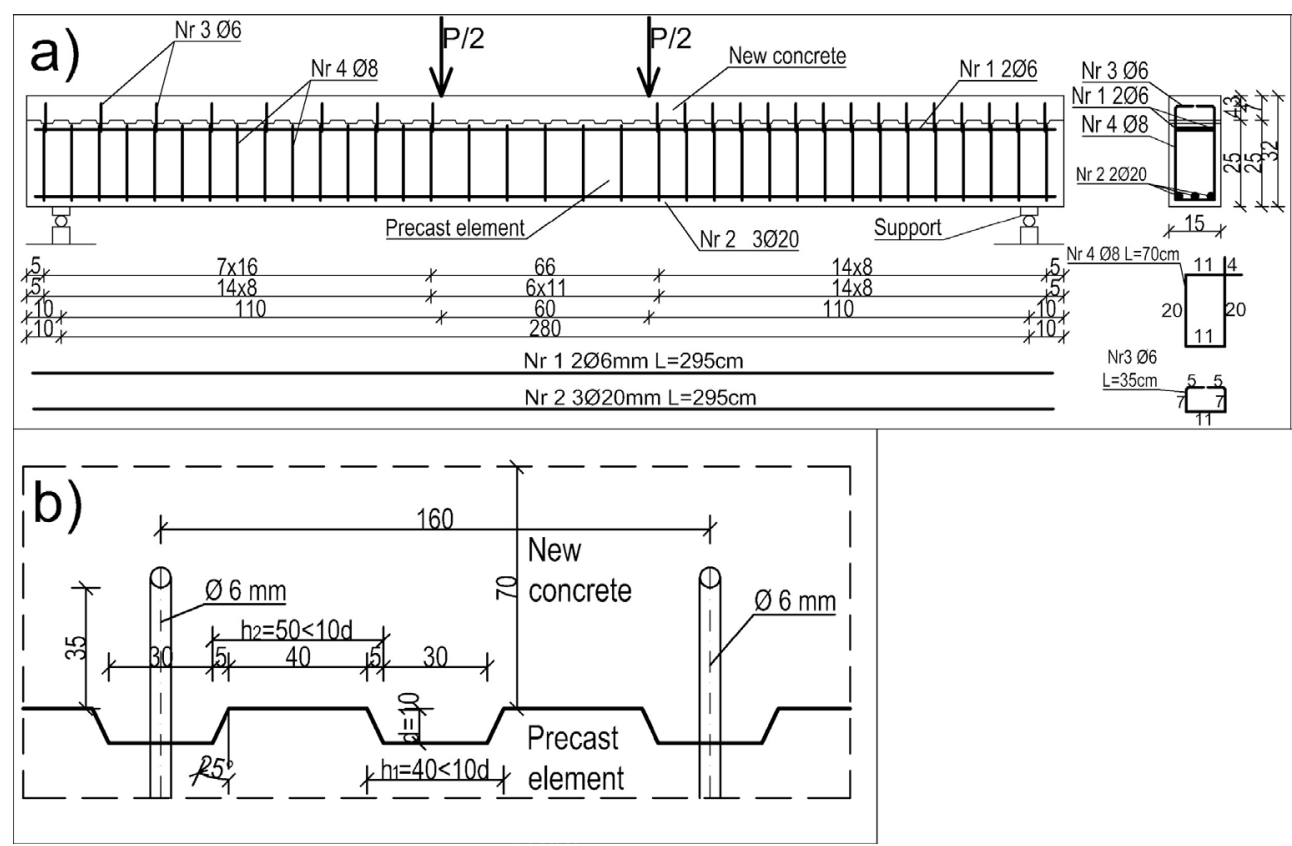

Fig. 1. Beam element a) dimensions and reinforcement scheme, b) precast surface with notches. Source: own study

The bottom reinforcement consisted of $3 \varnothing 20 \mathrm{~mm}$ ribbed bars made of $\mathrm{B} 500 \mathrm{~B}$ steel, the stirrups of $\varnothing 8 \mathrm{~mm}$ ribbed bars made of B500B steel were placed at $80 \mathrm{~mm}$ spacing in the support zones (1120 mm of both sides), while in the rest of beam the stirrup spacing was $110 \mathrm{~mm}$. Concrete layers were connected by a joining reinforcement consisting of two-armed $\varnothing 6 \mathrm{~mm}$ ribbed stirrups made of B500B steel at $160 \mathrm{~mm}$ spacing. New concrete was laid after 71 days of precast concrete curing. The precast elements were made of ready-mix class $\mathrm{C} 25 / 30$ concrete made with use of CEMI $42.5 \mathrm{R}$ cement. The shape of surface of the precast element as well as dimensions and arrangement of beam reinforcement are shown in Figure 1.

New concrete was made of CEM II/B-V 32.5N-LH/HSR/NA cement (producer Grupa Ożarów S.A.), fine 0-4 mm aggregate and gravel of 4-16 $\mathrm{mm}$. In order to obtain an appropriate consistency of the concrete mix BETOCRETE-F27 (FM) liquefying admixture in the amount of $1 \%$ of cement mass was used. The tap water was used. The class of new concrete was determined in accordance with PN-EN 206+A1: 2016-12 [7].

The following concrete parameters were determined using samples taken during concreting:

- compressive strength of concrete (10 samples of $150 \times 150 \times 150 \mathrm{~mm})$,

- tensile strength of concrete in splitting ( 6 samples of $150 \times 150 \times 150 \mathrm{~mm}$ ),

- modulus of concrete elasticity (3 cylinders of $\varnothing 150 \mathrm{~mm}, h=300 \mathrm{~mm}$ ).

The beam and samples were stored in the laboratory for 113 days (precast element) and 42 days (new concrete) until testing in air-dry conditions. The determined material parameters used later to describe the virtual model were presented in Table 1. 
Table 1. Material parameters of concrete and structural steel. Source: own study

\begin{tabular}{lllllll}
\hline Concrete & \multicolumn{7}{c}{ Steel } \\
\hline & $f_{\text {con.cube }}$ & $f_{\text {ctm }}$ & $E_{\text {cm }}$ & & $f_{\mathrm{y}}$ & $E_{\mathrm{s}}$ \\
& {$[\mathrm{MPa}]$} & {$[\mathrm{MPa}]$} & {$[\mathrm{GPa}]$} & & {$[\mathrm{MPa}]$} & {$[\mathrm{GPa}]$} \\
\hline New concrete & 43.57 & 2.40 & 31.85 & stirrups $\varphi 6$ & 545 & 200 \\
\hline Precast concrete & 36.30 & 2.30 & 27.99 & stirrups $\varphi$ 8 & 545 & 200 \\
\hline & & & & main reinforcement $\varphi$ 20 & 547 & 200 \\
\hline
\end{tabular}

\subsection{Description of the laboratory stand}

The test stand is equipped with Sylvac S_dial SWISS MODE electronic dial sensors for determining the deflections (sensors 7-9), support displacements (sensors 10-13), strain in the middle of the span (sensors 2-6, measuring base $\sim 200 \mathrm{~mm}$ ). The value of loading force $\mathrm{P}$ was read from the dynamometer (sensor 1). The load was applied to the element monotonously with the speed of about $2.7 \mathrm{kN} / \mathrm{min}$ until the element was damaged. The measurement results were recorded continuously at a frequency of 1 second and recorded in the data sheet. The diagram of the tested beam, the position of dial indicators and the location of zones for recording the results by digital cameras for image analysis are shown in Figure 2 (dial indicators were on the opposite side of the beam to the zones for image recording).

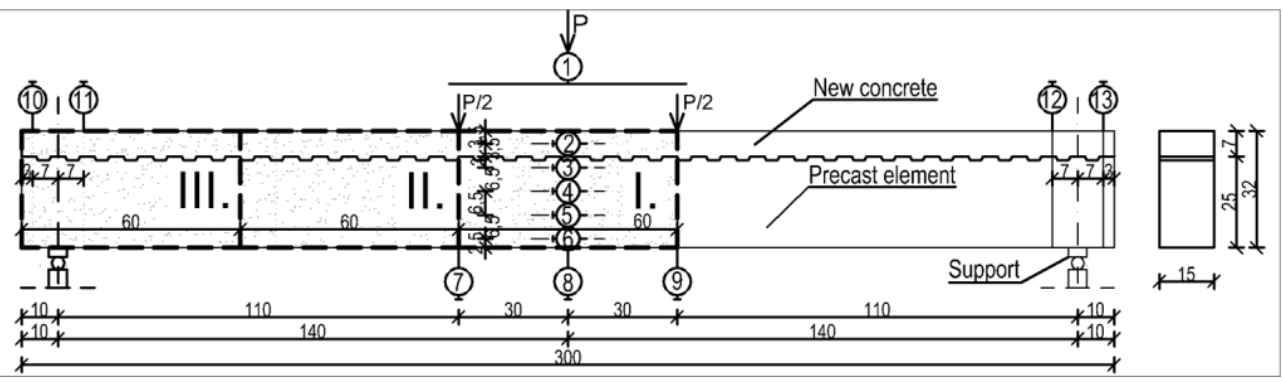

Fig. 2. The scheme of tested composite beam: position of dial indicators (1-13) and location of zones recorded by digital cameras (I. - III.). Source: own study

\subsection{Description of the digital image correlation method (DIC)}

2D image analysis was carried out using the Digital Image Correlation (DIC) method with GOM Correlate computer software [8]. The digital image correlation method requires an appropriate preparation of elements by painting the surface to be tested with white paint and marking the pattern of black dots, which are markers used in the photo processing.

Three 24-megapixel digital cameras with APS-C size CMOS sensors were used. Each of them took photos of a part of beam surface of approximately $320 \times 600 \mathrm{~mm}$ (as shown in Figure 2). Each part of the beam was photographed with one camera, then a $2 \mathrm{D}$ digital image correlation was executed. The photos were taken automatically every 20 seconds. The synchronization of photos with the results of the dial sensor measurement was achieved by correlating the internal time of digital cameras with a computer.

The method of digital image correlation consists in searching for elements with identical shapes in consecutive photos and determining the change of their coordinates. For this purpose the software assigns square or rectangular fields called "facets". In each field there is a unique pattern, which is directly used to analyse displacements and deformations. 
A detailed description of the principle of DIC method, preparation and performance of tests and inaccuracies of the method can be found in publications [2], [6], [9], [10].

\subsection{Description of finite element model (FEM 3D)}

The virtual model of a composite beam was created using the Abaqus/CEA 2019 software [11]. The symmetry of the beam allowed to model the beam half only as shown in Figure 3.

In order to reflect the concrete performance, the CDP (Concrete Damage Plasticity) model was used. This model allows to reflect the behavior of concrete in both the compressed and tensioned zones, as well as in zones of complex stress-strain state. The basic parameters describing the concrete behavior in the CDP model were presented in Table 2 based on literature sources [3], [12] and manual recommendations [11].

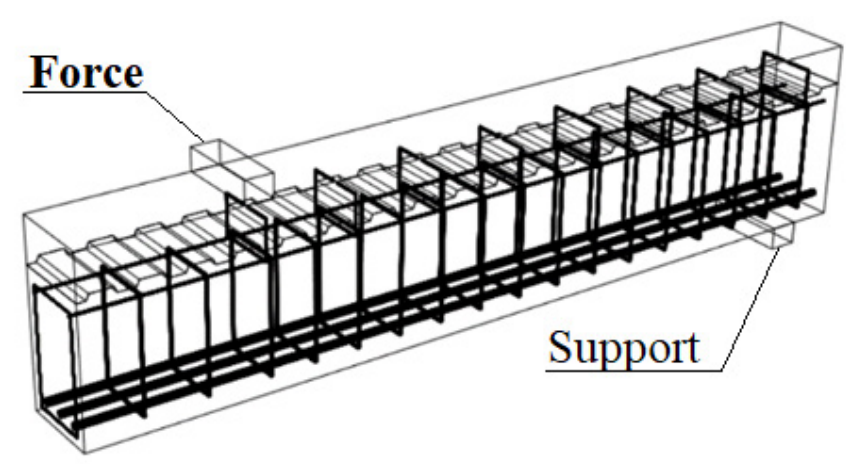

Fig. 3. 3D visualization of the numerical model of beam half. Source: own study

Table 2. CDP concrete model parameters used in numerical analysis. Source: own study based on [3]

\begin{tabular}{ll}
\hline Parameter name & Value \\
\hline$K_{\mathrm{c}}$ & 0.667 \\
\hline Eccentricity $\varepsilon$ & 0.1 \\
\hline $\mathrm{f}_{\mathrm{b} 0} / \mathrm{f}_{\mathrm{c} 0}\left(\sigma_{\mathrm{b} 0} / \sigma_{\mathrm{c} 0}\right)$ & 1.16 \\
\hline Dilation angle $\Psi$ & $36^{\circ}$ \\
\hline Viscosity parameter $\mu$ & 0.0001 \\
\hline
\end{tabular}

In order to correctly emulate the non-linear beam behaviour, it was necessary to assume the relation $\sigma-\varepsilon$ (stress-strain) for concrete and steel. On the basis of the tested parameters (Table 1), the "stress-strain" relationship for concrete under compression and tension, shown in Figure 4, was determined. The model also took into account the elastic degradation of concrete both under compression and tension, which was defined by the parameters $d_{\mathrm{t}}$ (tension) and $d_{\mathrm{c}}$ (compression). For reinforcing steel, an elastic-plastic model with hardening was adopted, which reflected the behaviour of the material in the tensile test of the steel sample. A detailed description of this procedure has been described in publications [3], [13]-[16] and in the manual [11]. 

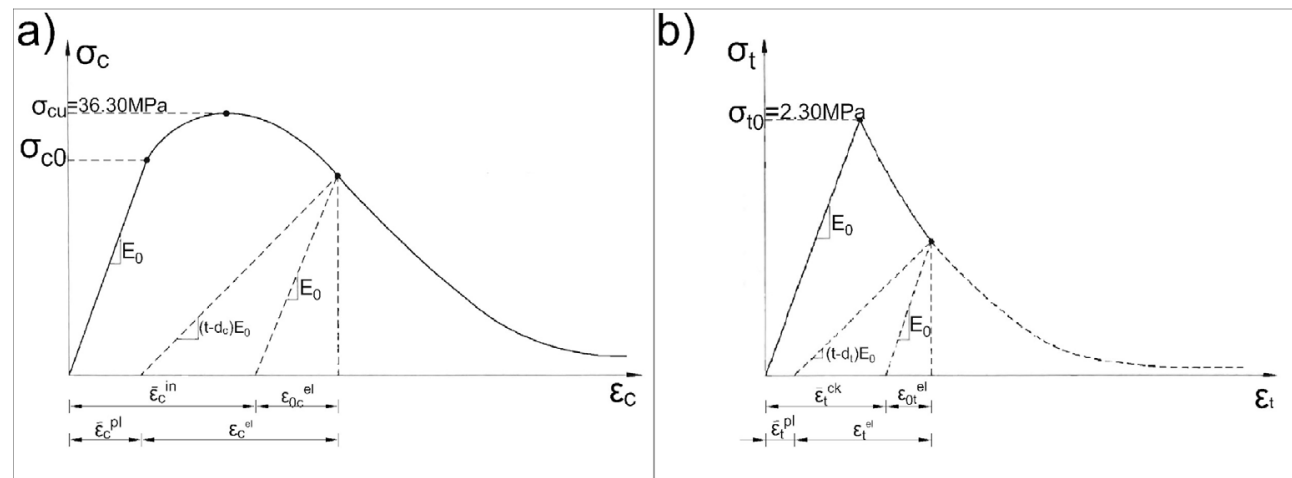

Fig. 4. "Stress-strain" relationship of the Concrete Damaged Plasticity (CDP) model, a) for single-axis compressed concrete, b) for tension concrete. Source: own study based on [11]

The composite beam model discreted in the Abaqus software consisted of steel reinforcement, precast element and new concrete. For the concrete elements, a finite element grid of about $25 \mathrm{~mm}$ mesh size was adopted. For its construction, eight-node solid elements of C3DR8 type were used. The steel reinforcement was modelled of beam elements B31 type. The cooperation between the reinforcement and concrete was achieved by adopting the "embedded" option (steel reinforcement was the embedded element and concrete was the base one). The applied forces and reactions of supports were transmitted through $150 \times 40 \times 40 \mathrm{~mm}$ steel pads (as in laboratory tests). A "surface-to-surface" contact model of "exponential" character was chosen to simulate the cooperation between precast elements and new concrete.

The cohesion between the concrete parts was modelled with the "traction-separation" function shown in Fig. 5. This function identifies the displacement of concrete parts in relation to each other ("separation") describing the behaviour of interface due to shear stress ("traction"). The relationship is linear-elastic at the beginning and after the damage initiation it changes into the so-called "damage evolution" state, also characterized by linearity.

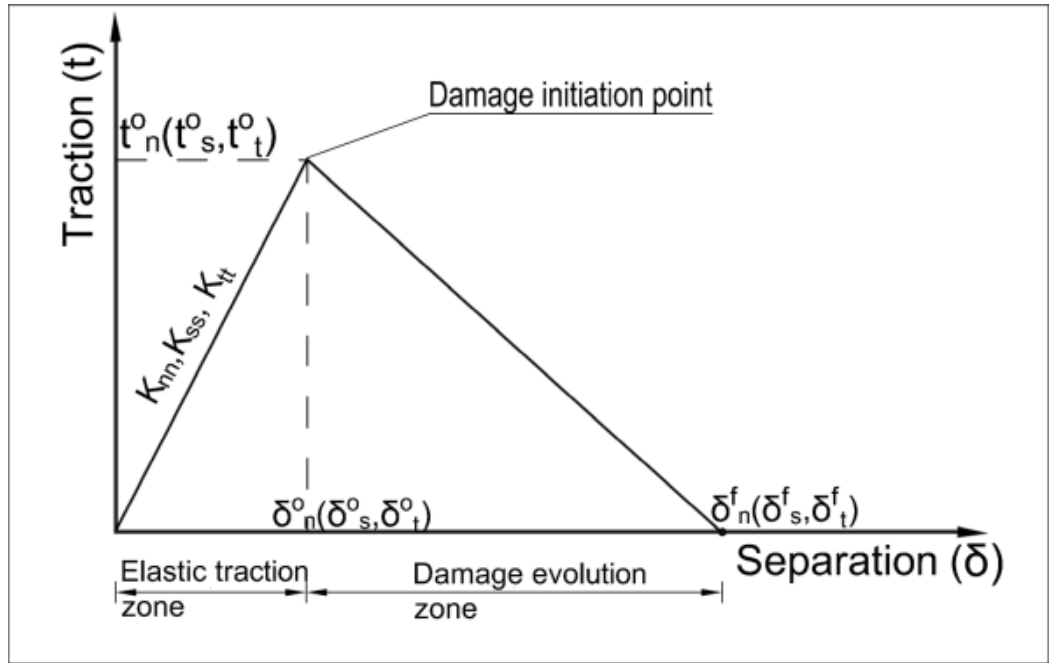

Fig. 5. The "traction-separation" relationship adopted for description of interface behaviour. Source: own study based on [11] 
The model calibration process was carried out assuming the friction coefficient of $\mu=0.7$, the traction at the damage initiation in all directions equal to concrete tensile strength $\left(t_{\mathrm{n}}^{\mathrm{o}}=t_{\mathrm{s}}^{\mathrm{o}}=t^{\mathrm{o}}=2.3 \mathrm{MPa}\right)$ and the separation at damage in all directions $\left(\delta_{\mathrm{t}}^{\mathrm{f}}, \delta_{\mathrm{s}}^{\mathrm{f}}, \delta_{\mathrm{t}}^{\mathrm{f}}\right)$ varied from 0.001 to $0.1 \mathrm{~mm}$. The value of stiffness of cohesive surface $\left(K_{\mathrm{nn}}, K_{\mathrm{ss}}, K_{\mathrm{tt}}\right)$ is assumed as the default one. The calibration was considered to be satisfactory when the obtained load which caused the interface cracking was similar to that identified by an imaging method. The best compliance with laboratory tests was achieved for a separation value of $0.005 \mathrm{~mm}$.

For the simulation of cracking phenomena, the $S D E G$ parameter was used, which describes the stiffness degradation of finite elements in the range from 0 to 1 . The stress in steel was presented with $S$,Mises parameter and the normal force in the interface along the $\mathrm{Z}$-axis was depicted with the CNORMF3 parameter.

The cracks between the new concrete and the precast element were illustrated also by means of the CSTATUS parameter, which determined the displacement of adjacent finite element nodes in relation to each other corresponded to the crack appearance. On the basis of model calibration it was assumed that the crack appeared if the slip between the concretes achieved the value of $0.005 \mathrm{~mm}$.

\section{Results and discussion}

The cracks of the beam identified by the DIC method and obtained with the finite element method were compared at different load levels. In addition, the stress in the interface and stirrups under the load causing interface crack were analysed.

Figure 6 shows cracks patterns of composite beams tested in the laboratory, identified by DIC method and that of the virtual model for different load levels.

The first bending cracks in the composite beam were observed by the DIC method under the load of $9.8 \mathrm{kN}$, while in the virtual beam model the cracks appeared under the load of $15.5 \mathrm{kN}$. Figure $6 \mathrm{a}$ shows the cracks under $20 \mathrm{kN}$ and $80 \mathrm{kN}$ loads. The perpendicular cracks in the pure bending zone under the load of $80 \mathrm{kN}$ are much more intense (greater range and width) than it was observed under the load of $20 \mathrm{kN}$. The next cracks appeared in the zone between support and force, but these did not yet crack due to the dominant shear.

For the same loads, the crack pattern shown in Figure 6b using the SDEG parameter indicates that the number of cracks in the virtual model and their length was less than that of the DIC method. This may be due to the fact that, according to the stiffness degradation parameter definition, a finite element is completely destroyed, which is identified as crack, after tensile stress in it reached a concrete tensile strength value. Meanwhile, the DIC method shows only the values of points displacements in relation to each other and it cannot be clearly stated whether the crack has already been formed (whether the concrete tensile strength has been achieved).

Under a load of about $80 \mathrm{kN}$, both methods indicate the appearance of shear cracks and the propagation of bending cracks (Fig. 6). 


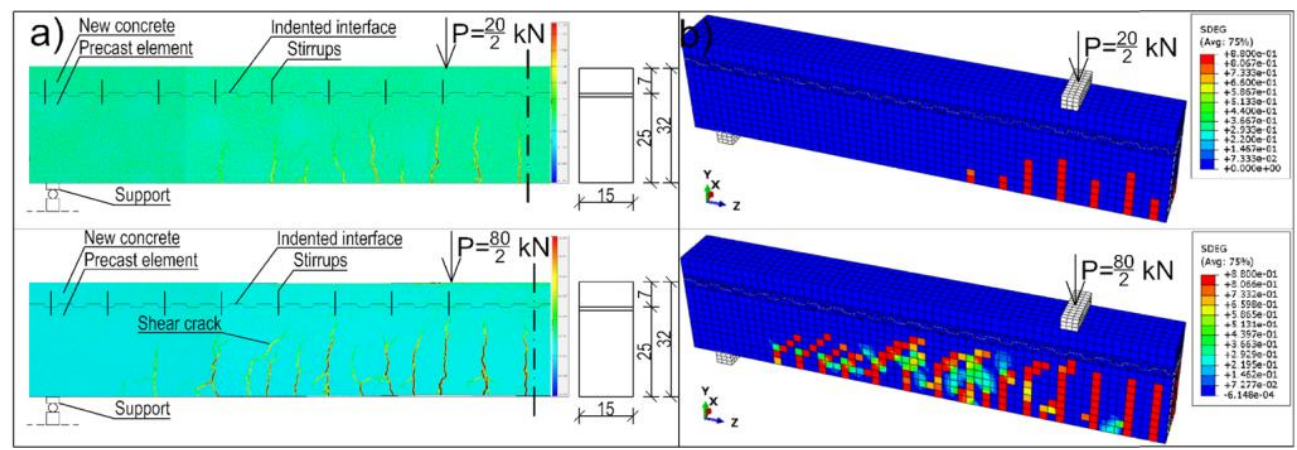

Fig. 6. Cracks pattern of the composite beam, a) beam displacements illustrated by GOM Correlate [8] for $20 \mathrm{kN}$ and $80 \mathrm{kN}$ loads, b) crack pattern generated by $S D E G$ parameter for $20 \mathrm{kN}$ and $80 \mathrm{kN}$ loads. Source: own study

The first symptoms of crack between new and precast concrete parts were observed at a load of $100.2 \mathrm{kN}$, as shown in Figure 7a. On detailed drawings of A and B areas, constituting the vertical (parallel to Y-axis) displacement maps, a horizontal crack in the down part of notch is visible. The crack was created in the place where there is no stirrup.

As the load increases, the cracks between concrete parts appear on the successive notches towards the support. The cracks pattern with a load of $180 \mathrm{kN}$ (Figure 7b) includes cracks due to bending, shear and interface cracks (marked with arrows in Figure 7b) on one side of notches without joining stirrups.

The cracks pattern of the virtual composite beam model obtained with use of the CSTATUS parameter is presented in Figure 8a. CSTATUS equal to $0.005 \mathrm{~mm}$, which was defined as the beginning of the crack (see chapter 2.3), was observed under a load of about $102 \mathrm{kN}$. Comparing the cracks observed with the DIC method and the CSTATUS and $S D E G$ parameters, it can be concluded that the place and time of interface cracks formation are related to formation and propagation of shear cracks. The places of separation in the contact plane are located on the line of shear cracks trajectory, where virtual rotation points may form.

The delamination between the concrete parts shown in Figure $8 \mathrm{~b}$ using the CSTATUS parameter for $180 \mathrm{kN}$ load confirms the interface cracking on one side of notches. Similar to the situation of lower load level, the interface cracks were associated with the formation and propagation of subsequent shear cracks. In the numerical model delamination took place in every notch. Therefore it can be concluded that the virtual model performance differed from the laboratory tests, in which the cracks between concrete parts occurred only at the notches, where there were no joining stirrups. 


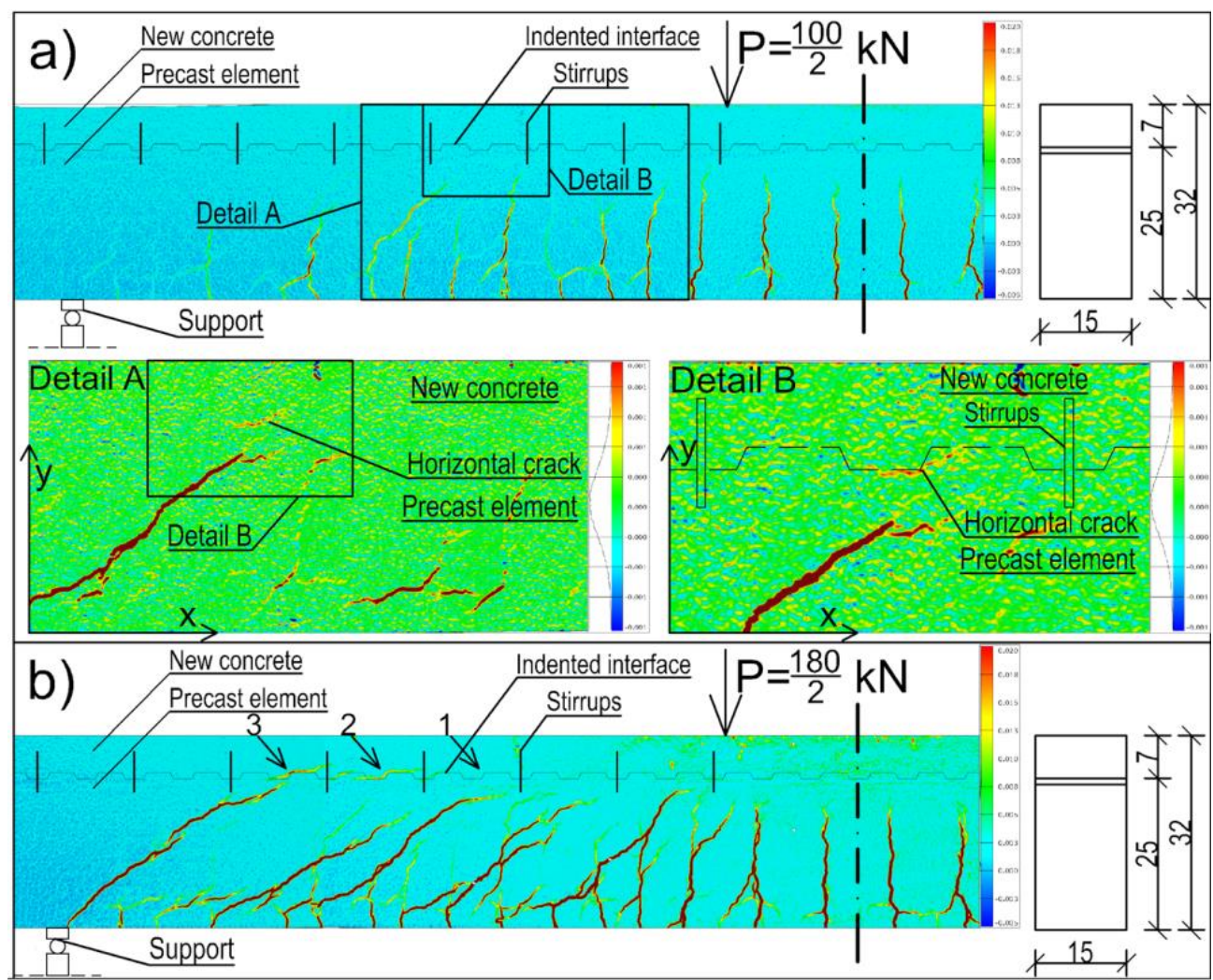

Fig. 7. Cracks pattern of the composite beam obtained with the GOM Correlate software [8] with use of Y-axis displacements, a) extensive view and details A and B under $100.2 \mathrm{kN}$ load, b) extensive view under $180 \mathrm{kN}$ load. Source: own study

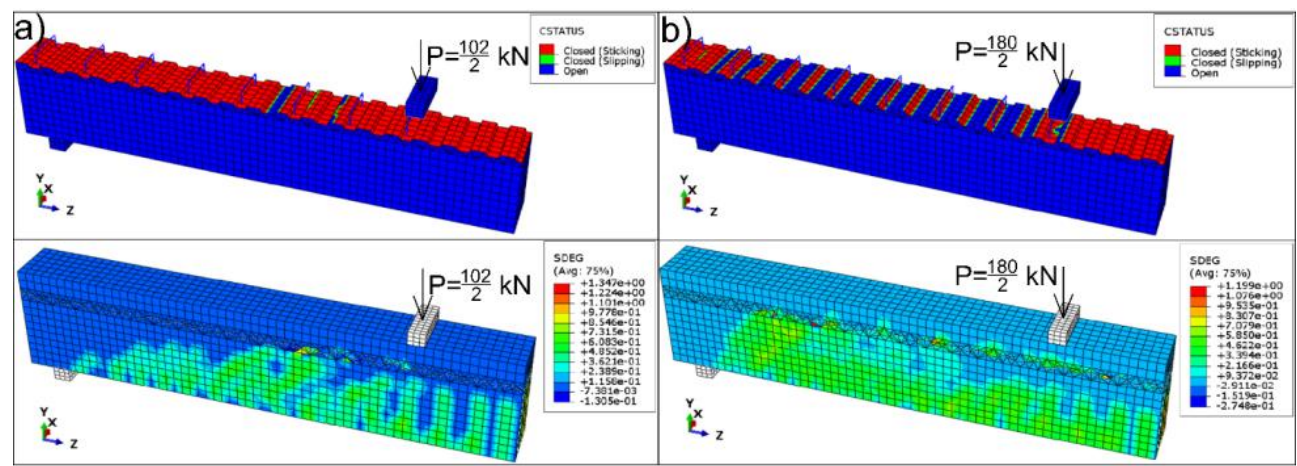

Fig. 8. Results of FEM analysis - cracks between concretes generated using CSTATUS parameter and cracks pattern shown with use of SDEG parameter, a) for load of $102 \mathrm{kN}$, b) for $180 \mathrm{kN}$ load. Source: own study 
Figure 9 shows the "load-deflection" relationship obtained in the laboratory test and in the virtual model. They are similar to each other up to a load of about 95-100 kN. These relationships differed after the interface cracking and the difference increases along with the increase of load. The deflection of tested composite beam under the ultimate load of $198 \mathrm{kN}$ was equal to $17.3 \mathrm{~mm}$, while under the same load the virtual model deflection was equal to $22.3 \mathrm{~mm}$. Differences in deflections are caused by the fact that interface cracks occur in each notch in the numerical model, whereas in tested beams only in few notches (Fig. 8b).

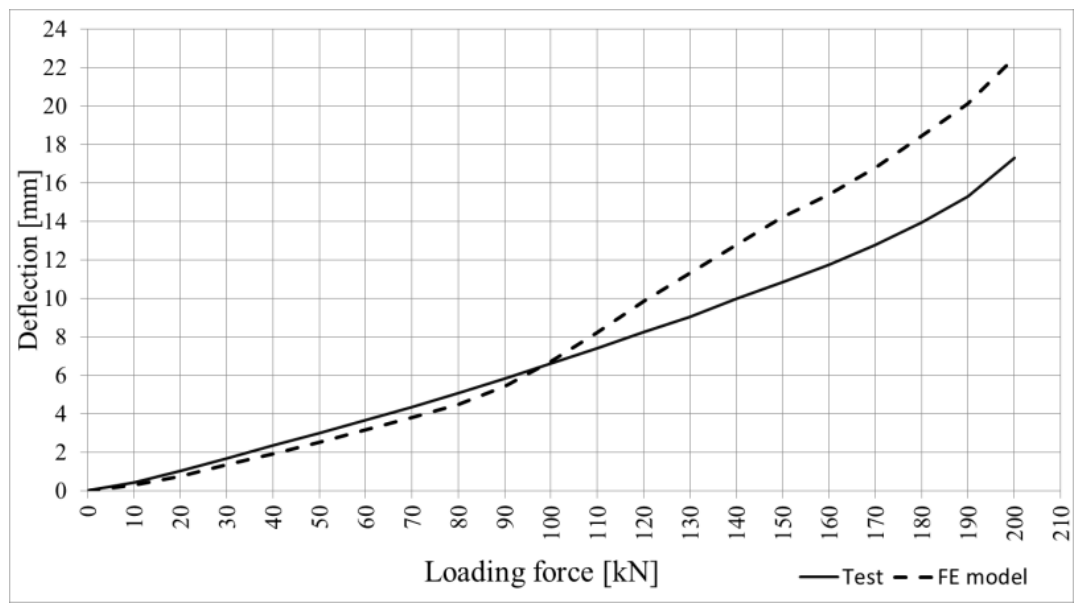

Fig. 9. "Load- deflection" relationship of the laboratory tested composite beam and its virtual model. Source: own study

Figure 10 shows a map of normal forces parallel to $Z$-axis for $102 \mathrm{kN}$ and $180 \mathrm{kN}$ loads expressed by the $C N O R M F 3$ parameter. In those notches where joining stirrups are present, there is a stress concentration which can be interpreted as an effect of "shear friction" phenomenon. As the load increases, normal stress increases and the range of their concentration grows towards the support, successively with the process of separation in successive notches.
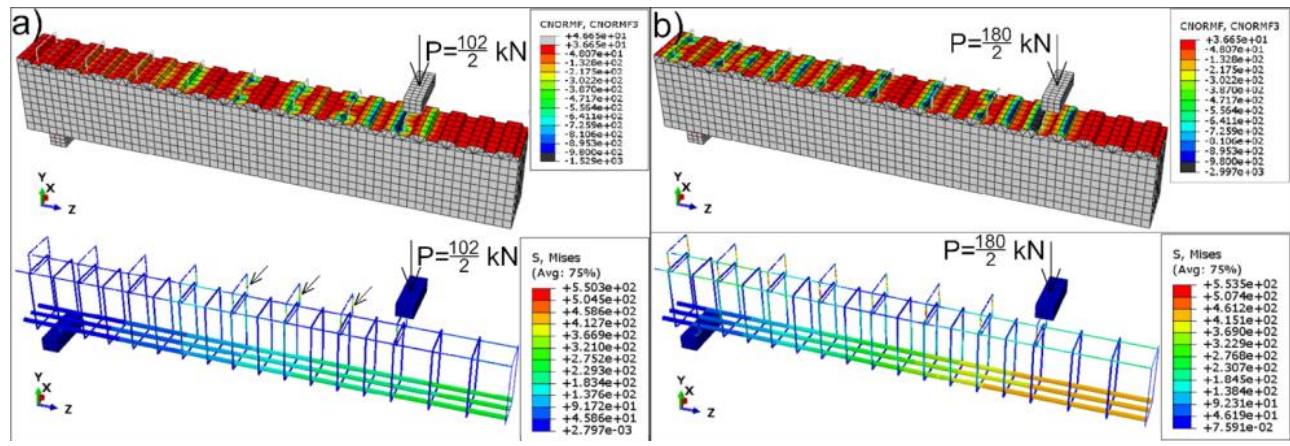

Fig. 10. Results of FEM analysis: "shear friction" presented using CNORMF3 and stress in the reinforcing steel presented with S,Mises parameter: a) for $102 \mathrm{kN}$ load, b) for $180 \mathrm{kN}$ load. Source: own study

The stresses in joining stirrups are shown in Figure 10 with use of the S,Mises parameter. Cracks between the concrete parts results in an increase in stress of the joining stirrups 
at the points marked with arrows in Figure 10a. This confirms the "dowel action" effect. The increase in stress of the subsequent joining stirrups (Figure 10b) is related to the debonding taking place in the subsequent notches towards the support.

Comparison of the laboratory results identified by the DIC method and finite element calculations shows that the virtual model reflects the composite beam performance properly up to the first crack between precast element and new concrete. In further work, the authors will make an attempt to improve the model in order to ensure that the interface cracks reflect the results of laboratory tests over the entire load range. The interface parameters obtained from the calibration will be used to analyze composite beams with different spacing and size of notches.

\section{Conclusion}

On the basis of comparative analysis of the performance of the composite beam with indented interface identified by the DIC method in laboratory test and the performance of its virtual model, the following conclusions can be specified:

- Cracks between the precast element and new concrete appear on the down part of that notches on the support side, where there are no joining stirrups. As the load increases, the cracks interface widen and new ones are formed in the subsequent notches towards the support.

- Formation of cracks in indented interface is related to the appearance and propagation of shear cracks.

- The effects of "shear friction" and "dowel action" phenomena are largely activated after interface cracking. The stress concentration on the notches' surface was observed near the joining stirrups, which confirms the occurrence of the above-mentioned phenomena.

- Virtual composite beam model of composite beam with indented interface and its calibration on the basis of laboratory test results identified by DIC method allows for an extended analysis of the composite behavior beam with the indented interface. The comparative analysis has shown that the results of both methods are comparable to the moment when interface cracked. The difference in deflection results from the fact that in a virtual model, the interface cracks occur at each notch, while in laboratory tests only in notches without joining stirrups. In further work make an attempt to improve the FE model by changing the parameters inter alia the friction coefficient, stiffness of cohesive surface and decrease mesh size.

\section{References}

[1] Halicka A., A study of the stress-strain state in the interface and support zones of composite structures with shrinkable and expansive concretes. Wydawnictwo Politechniki Lubelskiej, Lublin, 2007.

[2] Sadowski G. and Wydra M., "Comparison of methods applied to analysis of crack propagation in reinforced concrete composite beam", Acta Scientiarum Polonorum Architectura, vol. 1, no. 18, 2019, pp. 3-12. https://doi.org/10.22630/ASPA.2019.18.1.1

[3] Jabłoński Ł., Influence of surface parameters on static performance of concrete composite $t$-shaped beams. Wydawnictwo Politechniki Lubelskiej, Lublin, 2018.

[4] Henriques J., Simões da Silva L. and Valente I.B., "Numerical modeling of composite beam to reinforced concrete wall joints. Part I: Calibration of joint components", Engineering Structures, vol. 52, (July 2013), pp. 747-761. https://doi.org/10.1016/j.engstruct.2013.03.041 
[5] Henriques J., Simões da Silva L. and Valente I., "Numerical modeling of composite beam to reinforced concrete wall joints. Part II: Global behavior", Engineering Structures, vol. 52, (July 2013), pp. 734-746. https://doi.org/10.1016/j.engstruct.2013.03.040

[6] Szczecina M., Tworzewski P. and Uzarska I., "Numerical modeling of reinforced concrete beams, including the real position of reinforcing bars", Structure and Environment, vol. 10, no. 1, 2018, pp. 28-38. https://doi.org/10.30540/sae-2018-003

[7] PN-EN 206+A1:2016-12, Concrete - Specification, performance, production and conformity.

[8] GOM Correlate - Software for 3D Testing Data. Free trial license. Available: http://www.gom. com/3d-software/gom-correlate/ [Access: 15 Dec 2019]

[9] Aggelis D.G. et al., "Characterization of mechanical performance of concrete beams with external reinforcement by acoustic emission and digital image correlation", Construction and Building Materials, vol. 47, 2013, pp. 1037-1045. https://doi.org/10.1016/j.conbuildmat.2013.06.005

[10] Tsangouri E. et al., "Detecting the activation of a self-healing mechanism in concrete by acoustic emission and digital image correlation", The Scientific World Journal, vol. 2013, p. 10, 2013. https://doi.org/10.1155/2013/424560

[11] Dassault Systèmes Simulia, Abaqus 6.1 2, Abaqus 6.12, 2012.

[12] Kmiecik P., Kamiński M., "Modelling of reinforced concrete structures and composite structures with concrete strength degradation taken into consideration", Archives of Civil and Mechanical Engineering, vol. 11, iss. 3, 2011, pp. 623-636. https://doi.org/10.1016/S1644-9665(12)60105-8

[13] Chen G.M., Chen J.F. and Teng J.G., "On the finite element modelling of RC beams shear-strengthened with FRP", Construction and Building Materials, vol. 32, (July 2012), pp. 13-26. https://doi. org/10.1016/j.conbuildmat.2010.11.101

[14] Chen G.M., Teng J.G., and Chen J.F., "Finite-Element Modeling of Intermediate Crack Debonding in FRP-Plated RC Beams", Journal of Composites for Construction, vol. 15, iss. 3, (June 2011). https://doi.org/10.1061/(ASCE)CC.1943-5614.00001572011

[15] Smarzewski P., "Numerical analysis of inelastic reinforced high-strength concrete beams with low reinforcement ratio", Budownictwo i Architektura, vol. 4, no. 1, 2009, pp. 4-30.

[16] Sinaei H. et al., Evaluation of reinforced concrete beam behaviour using finite element analysis by ABAQUS, Scientific Research and Essays, vol. 7, no. 20, 2012. 